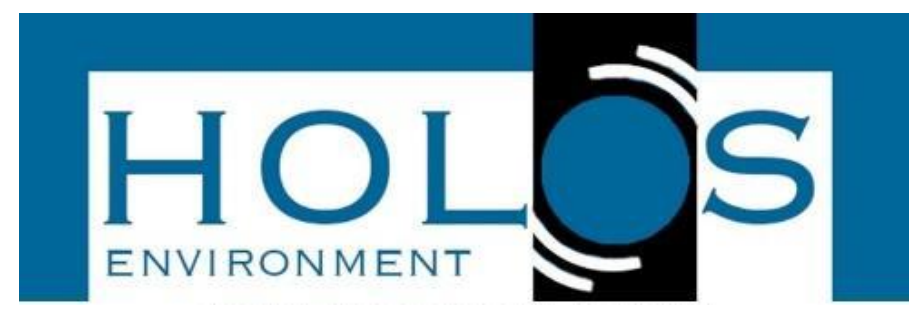

\title{
AVALIAÇÃO DAS CARACTERÍSTICAS FíSICAS DA BACIA HIDROGRÁFICA DO RIO PARIQUERA-AÇU NO BAIXO RIBEIRA DE IGUAPE (SP)
}

\author{
EVALUATION OF PHYSICAL CHARACTERISTICS OF PARIQUERA-AÇU RIVER \\ WATERSHED IN LOW RIBEIRA DE IGUAPE VALLEY, SAO PAULO STATE, BRAZIL
}

\author{
Pedro Henrique dos Santos Coliado ${ }^{\text {; }}$ Vanessa Cezar Simonetti ${ }^{2}$; Darllan Collins da Cunha e Silva ${ }^{1}$
}

Artigo recebido em: 12/04/2020 e aceito para publicação em: 20/04/2020.

DOI: http:/dx.doi.org/10.14295/holos.v20i3.12386

\begin{abstract}
Resumo: As características morfométricas das bacias hidrográficas são elementos essenciais para a avaliação do comportamento hidrológico e sua relação com a maximização ou minimização dos impactos ambientais. Dessa forma, o objetivo deste estudo foi analisar a morfometria da bacia hidrográfica do rio Pariquera-Açu no Baixo Ribeira de Iguape (SP) com o uso de técnicas geoprocessamento, visando obter informações que forneçam subsídios para o planejamento e gestão desta área quanto à preservação, racionalização do seu uso e recuperação ambiental. A bacia hidrográfica possui uma área de $345,27 \mathrm{~km}^{2} \mathrm{e}$ suas principais atividades econômicas provém do cultivo de chá e banana. As curvas de nível foram extraídas do Modelo Digital do Terreno (MDT) do satélite japonês Alos e a hidrografia das cartas topográficas do Instituto Geográfico e Cartográfico (IGC) para determinação dos índices morfométricos. Os resultados demonstraram que os valores medianos da densidade de drenagem, associados à presença de áreas planas e baixo coeficiente de rugosidade, facilitam a infiltração da água no solo, diminuindo o escoamento superficial, bem como o risco de erosão e degradação ambiental, e, ainda, propicia o desenvolvimento agrícola. Os valores baixos do índice de circularidade e do coeficiente de compacidade indicam que a bacia tende a ser alongada, com menor suscetibilidade à ocorrência de enchentes acentuadas. Entretanto, devido ao relevo suave nas áreas próximas aos cursos de água podem ocorrer episódios de enchentes, portanto, estas áreas devem receber uma atenção especial por parte dos gestores públicos ao que tange o monitoramento e ações de conservação.
\end{abstract}

Palavras-chave: Morfometria. Hidrografia. SIG. Relevo.

\begin{abstract}
The morphometric characteristics of watersheds are essential elements for the assessment of hydrological behavior and its relationship with the maximization or minimization of environmental impacts. Thus, the aim of this study was to analyze the morphometry of Pariquera-Açu River watershed in low Ribeira de Iguape Valley in Sao Paulo State, Brazil with the use of geoprocessing technical, in order to obtain information that provides subsidies for the planning and management of this area regarding preservation. The basin covers an area of $345.27 \mathrm{~km}^{2}$ and its main economic activities comes from the tea and banana cultivation. The contours were extracted from the Digital Terrain Model (DTM) of the Japanese satellite Alos and the hydrography of the topographic maps of the Geographic and Cartographic Institute $(\mathrm{GCl})$ to determine the morphometric indices. The results demonstrated that the median values of drainage density associated to the presence of lowland areas and low roughness coefficient, facilitate the infiltration of water into the soil, decreasing runoff as well as the risk of erosion and environmental degradation and provides agricultural development. The low values of the circularity index and the compactness coefficient indicate that the basin tends to be elongated with less susceptibility to the occurrence of accentuated floods. However, due to the flat relief in the areas close to the water courses episodes of flooding may occur. Therefore, these areas should receive special attention from public managers regarding monitoring and conservation actions.
\end{abstract}

Keywords: Morphometry. Hydrography. GIS. Relief.

\footnotetext{
1Universidade Estadual Paulista (Unesp), Campus de Registro, SP, Brasil. E-mail: (pedrocoliado@hotmail.com, darllan.collins@unesp.br) ${ }^{2}$ Universidade Estadual Paulista (Unesp), Instituto de Ciência e Tecnologia, Sorocaba, SP, Brasil. E-mail: (va simonetti@hotmail.com)
} 


\section{INTRODUÇÃO}

A bacia hidrográfica é uma unidade de gestão territorial importante para os estudos ambientais, pois todos os componentes pertencentes a ela, tais como geologia, geomorfologia, cobertura vegetal, clima e rios estão integrados e interligados; portanto, qualquer alteração nesses compartimentos pode impactar nesse ambiente, principalmente no que concerne a qualidade e quantidade de água disponível para a sobrevivência humana e o desenvolvimento da sociedade (FAUSTINO et al., 2014).

Nesse sentido, a adoção da bacia hidrográfica como unidade de gestão territorial é fundamental para a preservação dos recursos hídricos, pois, as mudanças de disponibilidade dos recursos hídricos apresentam impactos diretos no meio ambiente e na ocupação do solo pela agricultura (MELLO; SILVA, 2013).

A adoção de técnicas e cálculos para quantificar e caracterizar morfometricamente as bacias hidrográficas são de importância fundamental para auxiliar no planejamento dessas áreas com a finalidade de preservação ambiental e manutenção da quantidade e qualidade da água (ROCHA; KURTZ, 2001; SILVA et al., 2016).

Estes parâmetros podem revelar indicadores físicos específicos para um determinado local, de forma a qualificarem as alterações ambientais (ANTONELI; THOMAZ, 2007). Para Santos et al. (2012), as características morfométricas das bacias hidrográficas são elementos essenciais para a avaliação do comportamento hidrológico e sua relação com a maximização ou minimização dos impactos ambientais. Portanto, os parâmetros morfométricos devem ser considerados no conjunto para caracterizar a bacia e devem ser utilizados como importantes pressupostos na elaboração de projetos de prevenção e defesa contra eventos hidrológicos, como estiagens e enchentes que ocorrem na bacia hidrográfica (CAMPOS et al., 2015).

Vários estudos científicos utilizaram Sistemas de Informação Geográfica (SIG) para extrair informações morfométricas de bacias hidrográficas e estabelecer uma relação entre esses dados com a preservação ambiental dessas importantes unidades de gestão, permitindo, assim, servir de instrumento norteador para os tomadores de decisão (CAMPOS et al., 2015; FERREIRA et al., 2015; FRAGA et al., 2014; MORELI et al., 2014).

Diante do exposto, o objetivo deste estudo foi analisar a morfometria da bacia hidrográfica do rio Pariquera-Açu no Baixo Ribeira de Iguape (SP) com o uso de técnicas geoprocessamento, visando obter informações que forneçam subsídios para o planejamento e gestão desta área. 


\section{MATERIAL E MÉTODOS}

\section{1 Área de estudo}

A bacia hidrográfica do rio Pariquera-Açu está inserida nos municípios de Iguape (SP) e Pariquera-Açu (SP), os quais pertencem ao Vale do Ribeira, numa região localizada ao Sul do estado de São Paulo, no Brasil (Figura 1). Segundo estimativas do Instituto Brasileiro de Geografia e Estatística (IBGE) para o ano de 2019, os municípios de Iguape (SP) e Pariquera-Açu (SP) têm, respectivamente, uma população de 30.857 habitantes e de 19.648 habitantes (IBGE, 2019).

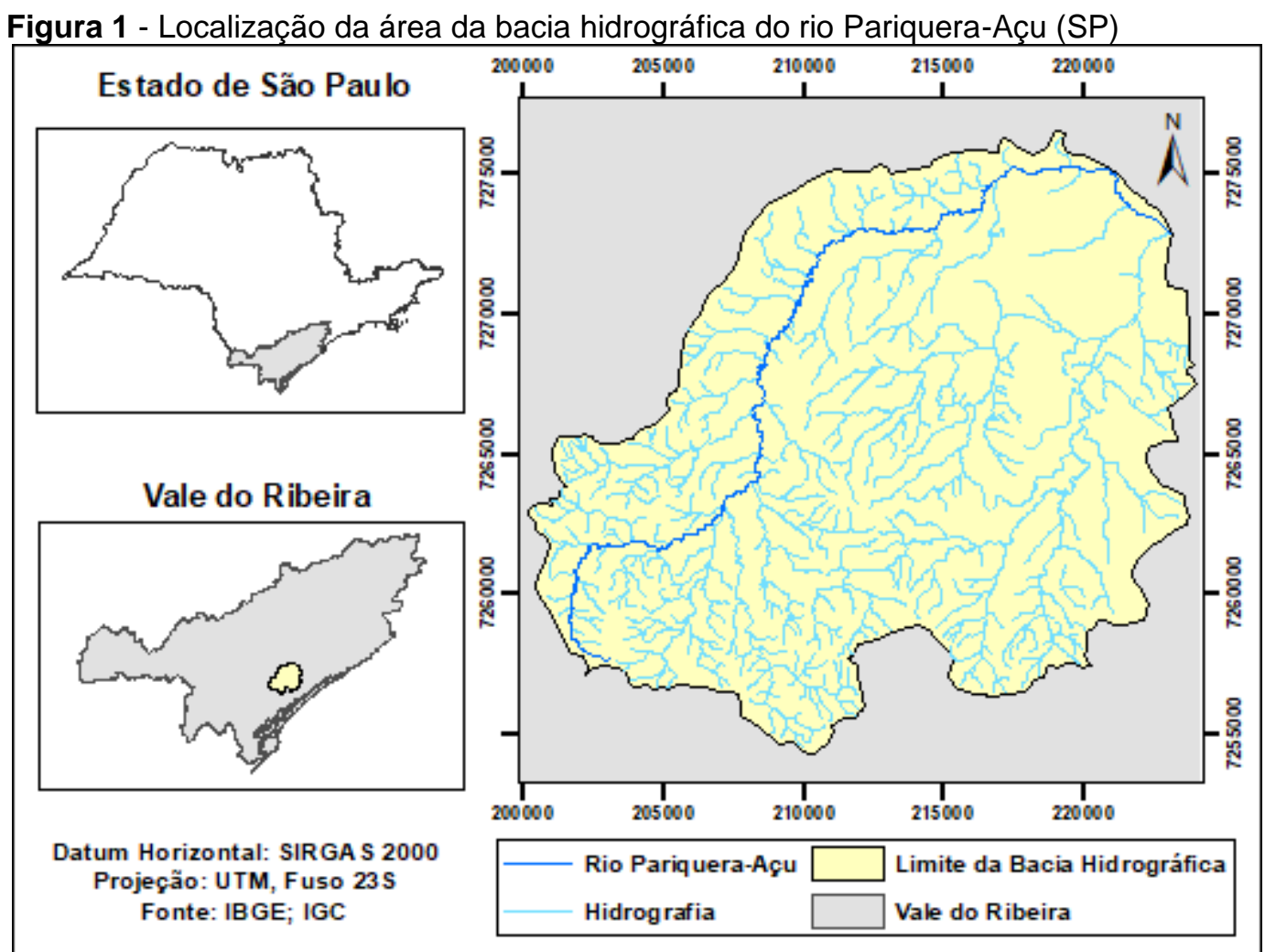

Fonte: Elaborado pelos autores.

O clima predominante na bacia é do tipo subtropical úmido com quatro estações bem definidas, apresentando invernos frios com temperaturas em torno de $13^{\circ} \mathrm{C}$ e verões quentes com temperaturas em torno de $29^{\circ} \mathrm{C}$. A pluviosidade anual varia entre 1700 a 1800 $\mathrm{mm}$ com temperatura média anual em torno dos $23^{\circ} \mathrm{C}$ (DIAS; OLIVEIRA, 2015).

O rio Pariquera-Açu é um tributário direto do rio Ribeira de Iguape, principal curso de água localizado no Vale do Ribeira (SIGRH, 2019). As principais atividades econômicas 
desenvolvidas nesta bacia são a pecuária e a agricultura, com destaque para o cultivo de chá e banana (CUNHA; CALIJURI, 2010).

\subsection{Procedimento Metodológico}

Para delimitar a área de estudo foi vetorizada a hidrografia presente nas cartas topográficas do Instituto Geográfico e Cartográfico (IGC) na escala de 1:50.000. Enquanto que a topografia do local foi obtida a partir dos dados topográficos do satélite japonês Alos, lançado pela pela Japan Aerospace Exploration Agency - JAXA, no centro espacial de Tanegashima (Japão), na escala de 1:62.000, com resolução espacial de 12,5m. Após a vetorização da hidrografia e construção do Modelo Digital de Elevação (MDE) foram determinados os parâmetros dimensionais da bacia, como: comprimento do rio principal $(\mathrm{Cp})$, que corresponde à representação horizontal das sinuosidades do rio principal, desde sua nascente até a foz; comprimento total da rede de drenagem (Cd) que acompanha as sinuosidades do rio principal e dos tributários; perímetro $(\mathrm{P})$ correspondente ao comprimento da linha do divisor de águas que circunda a bacia; e a área $(A)$ da bacia delimitada pelos divisores de água.

Esses valores subsidiaram os cálculos dos indicadores relacionados à forma da bacia como o coeficiente de compacidade (Kc) e o índice de circularidade (Ic).

O Kc é um número adimensional que varia com a forma da bacia, independentemente de seu tamanho, assim quanto mais irregular ela for, maior será o coeficiente de compacidade, em contrapartida, quanto mais próxima da unidade, mais circular será a bacia e, consequentemente estará mais sujeita a enchentes (SILVA et al., 2016). Para a determinação do Kc foi utilizada a Equação (1).

$K c=\frac{0,28 \times P}{\sqrt{A}}$

Sendo:

$\mathrm{P}$ é o comprimento da bacia hidrográfica $(\mathrm{m})$;

A é a área de drenagem da bacia hidrográfica $\left(\mathrm{m}^{2}\right)$.

O Índice de Circularidade (Ic) é um parâmetro que avalia a forma da bacia e tende para o valor igual a 1 à medida que a bacia se aproxima da forma circular e diminui à medida que a forma se torna mais alongada. Segundo Machado e Torres (2012), o Ic é a relação 
existente entre a área de uma bacia hidrográfica $(A)$ com área de um círculo que tem a mesma dimensão que o perímetro da bacia hidrográfica $(P)$. Para determinar o lc foi utilizada a Equação (2).

$I c=\frac{4 \pi A}{P^{2}}$

Quanto às características relacionadas a rede de drenagem, foram estudadas a ordem, densidade de drenagem, gradiente de canais, extensão do percurso superficial da enxurrada, coeficiente de manutenção e índice de sinuosidade dos canais.

A ordem da bacia (W) é uma classificação da rede de drenagem com a identificação e quantificação de todos os canais. Para isso, foram utilizados os critérios introduzidos por Strahler (1952), no qual para os cursos d'água sem tributários é adotada a ordem "1", ou primeira ordem, enquanto que os cursos de água de segunda ordem originam-se da confluência de dois cursos de água de primeira ordem, podendo ter tributários também de primeira ordem; os cursos de água de terceira ordem originam-se da confluência de dois cursos de água de segunda ordem, podendo receber tributários de segunda e primeira ordens e assim sucessivamente. A ordem da bacia é determinada pelo curso de água de ordem maior.

A densidade de drenagem $(\mathrm{Dd})$ corresponde à relação entre o comprimento total de rios da bacia hidrográfica (Lt) e a sua respectiva área $(A)$, sendo determinado pela Equação (3). Segundo Villela e Mattos (1975), os valores para a densidade de drenagem variam de $0,5 \mathrm{~km} / \mathrm{km}^{2}$ para bacias com drenagem pobre, e $3,5 \mathrm{~km} / \mathrm{km}^{2}$ ou mais para bacias excepcionalmente bem drenadas.

$D d=\frac{L t}{A}$

O gradiente de canais tem por finalidade indicar a declividade dos cursos d'água (HORTON, 1945), sendo este determinado pela Equação (4)

$G c=\frac{A M}{C c p} \times 100$

Sendo: 
Gc - Gradiente de canais em \%;

AM - Altitude máxima em m;

Ccp - Comprimento do canal principal em $\mathrm{m}$.

A extensão do percurso superficial da água de enxurrada (Eps) representa a distância média percorrida pelas enxurradas antes de encontrar um canal permanente (CHRISTOFOLETTI, 1969), sendo o Eps determinado pela Equação (5).

Eps $=0,5 \times D d \times 1000$

Sendo:

Eps - Extensão do percurso superficial da água de enxurrada em m;

Dd - Densidade de drenagem em $\mathrm{Km} / \mathrm{Km}^{2}$

O coeficiente de manutenção dos canais $(\mathrm{Cm})$ foi proposto por Schumm (1956), como o inverso da densidade de drenagem (Dd), expresso na Equação (6). Essa constante, cuja unidade é $\mathrm{km}^{2} / \mathrm{km}$, tem dimensão de comprimento e aumenta em magnitude conforme a área de contribuição aumenta. Especificamente, este demonstra a área de drenagem $\left(\mathrm{km}^{2}\right)$ necessária para sustentar um quilômetro linear de canal.

$C m=1 / D d$

O índice de sinuosidade (Is) relaciona o comprimento verdadeiro do canal (projeção ortogonal) com a distância vetorial (comprimento em linha reta) entre dois extremos do canal principal, de acordo com a Equação (7). Valores próximos a 1,0 indicam que o canal tende a ser retilíneo, enquanto que valores superiores a 2,0 sugerem canais tortuosos (LANA, 2001).

$I s=C c p / d v$

Sendo:

Ccp - Comprimento do canal principal em Km;

dv - Distância vetorial em Km.

Em relação às características relacionadas ao relevo, foram determinadas a amplitude altimétrica, a razão do relevo, a estratificação da declividade e o coeficiente de 
rugosidade. A amplitude altimétrica é calculada pela diferença entre a maior altitude à montante e a menor altitude à jusante da bacia.

A razão de relevo $(\mathrm{Rr})$ é determinada pela relação entre a diferença de altitude dos pontos extremos da bacia $(H)$ e o seu maior comprimento $(C)$, que corresponde a direção do vale principal, entre a foz e o ponto extremo sobre a linha do divisor de águas (SCHUMM, 1956), sendo determinado pela Equação (8). Este indicador permite comparar a altimetria das regiões, demonstrando que, quanto maiores os valores, mais acidentado é o relevo predominante na região, consequentemente, maior será o escoamento superficial das águas pluviais, refletindo numa menor infiltração e aumentando os riscos de erosão.

$R r=H / C$

As classes de declividade foram estratificadas em seis intervalos levando em consideração a classificação proposta pela Embrapa (1999), sendo os seguintes intervalos de declividades (em \%) adotados: de 0 a $3 \%$ relevo plano; de 3 a 6 \% suave ondulado; de 6 a $12 \%$ ondulado; de 12 a $20 \%$ forte ondulado; de 20 a $40 \%$ montanhoso; e maior que $40 \%$ escarpado.

O Coeficiente de Rugosidade (RN) será determinado pela multiplicação da declividade média (D) encontrada em cada ponto (pixel) pelo valor numérico da densidade de drenagem (Dd), como pode ser visto pela Equação (9).

$R N=D \times D d$

Quanto maior o valor do RN, maior o risco de erosão. Em função disso, Rocha e Kurtz (2001) estabeleceram quatro classes de aptidão do uso do solo para avaliar o uso potencial dos solos, sendo elas: Agricultura; Pastagem/Pecuária; Pastagem/Florestamento e Florestamento, sendo que estas foram utilizadas para identificar as aptidões de diversas áreas presente na bacia hidrográfica. Para caracterizar essas classes foi calculado o Intervalo de Classe ( $\operatorname{InC}$ ) referente aos coeficientes de rugosidades de classe, conforme a Equação (10), sendo que, a definição dos intervalos de domínios das classes de RN's, se iniciará com a classe inferior, a fim de incluir o menor valor de RN, após isso, acrescentase o valor do intervalo de classe ( $\operatorname{lnC}$ ), definindo-se, deste modo, o limite superior do intervalo, conforme proposto por Rocha e Kurtz (2001). 
$\operatorname{In} C=\frac{\left(\mathrm{RN}_{\text {maior }}-\mathrm{RN}_{\text {menor }}\right)}{4}$

Sendo:

$\mathrm{RN}_{\text {maior }}$ é o maior valor de $\mathrm{RN}$ encontrado na bacia hidrográfica;

$\mathrm{RN}_{\text {menor }}$ é o menor valor de $\mathrm{RN}$ encontrado na bacia hidrográfica.

Todo o procedimento metodológico foi desenvolvido com o auxílio do Sistema de Informação Geográfica (SIG) QGis versão 2.4 e ArcGIS 10.6.

\section{RESULTADOS E DISCUSSÃO}

Os dados da Tabela 1 apresentam a ordem da bacia hidrográfica do curso de água principal e os parâmetros que descrevem as características físicas, de forma e relevo que foram identificados e quantificados.

Tabela 1 - Parâmetros Dimensionais da bacia do rio Pariquera-Açu no baixo Ribeira de Iguape (SP)

Parâmetros Dimensionais das Características Físicas da Bacia

\begin{tabular}{lcc}
\hline Área (A) & $\mathrm{Km}^{2}$ & 345,27 \\
Perímetro (P) & $\mathrm{Km}$ & 89,42 \\
Ordem da bacia (W) & - & $6 \underline{\mathbf{a}}$ \\
Coeficiente de compacidade (Kc) & - & 1,35 \\
Índice de circularidade (Ic) & - & 0,54 \\
Comprimento total de rios da bacia (Lt) & $\mathrm{Km}$ & 592,05 \\
Comprimento do rio principal (Cp) & $\mathrm{Km}$ & 42,49 \\
Densidade de drenagem (Dd) & $\mathrm{Km} / \mathrm{Km}^{2}$ & 1,71 \\
Gradiente de canais (Gc) & $\%$ & 0,51 \\
Extensão do percurso superficial da água de enxurrada (Eps) & $\mathrm{m}$ & 856 \\
Coeficiente de manutenção (Cm) & $\mathrm{m}^{2} / \mathrm{m}$ & 584 \\
Índice de sinuosidade (Is) & $\mathrm{Km} / \mathrm{Km}$ & 1,7 \\
Coeficiente de rugosidade (RN) & - & 291,65 \\
Razão de Relevo (Rr) & $\%$ & 1,57 \\
Intervalo de Classe (InC) & $\mathrm{m}$ & 72,91 \\
\hline Fonte: Elarado pelos
\end{tabular}

Fonte: Elaborado pelos autores.

O índice de compacidade calculado (Kc) apresentou o valor de 1,35, um valor mediano, o que significa que a bacia não tem alta propensão a grandes enchentes, mas também não está isenta desse tipo de ocorrência. Já o índice de circularidade (IC) encontrado foi de 0,54 , sendo que lc=0,51 representa um nível moderado de escoamento, não contribuindo na concentração de águas que possibilitem cheias abruptas (MÜLLER, 
1953; SCHUMM, 1956), sendo assim, os valores obtidos para este índice estão próximos da neutralidade.

A densidade de drenagem (Dd), segundo Villela e Mattos (1975), varia entre 0,5 $\mathrm{Km} / \mathrm{Km}^{2}$ para bacias hidrográficas pobres e $3,5 \mathrm{Km} / \mathrm{Km}^{2}$ para as excepcionalmente drenadas (o que ocorre em regiões de fácil erosão, declives ou de baixa vegetação), visto isso, a bacia do rio Pariquera-Açu (Dd) pode ser considerada como mediana, pois apresenta uma drenagem de $1,71 \mathrm{Km} / \mathrm{Km}^{2}$.

As bacias hidrográficas com esses respectivos valores de densidade de drenagem tendem a um baixo escoamento superficial e maior infiltração, fazendo com que a água deixe a bacia hidrográfica com menor velocidade. Em outras palavras, para um mesmo clima, a Dd depende do comportamento hidrológico dos solos e rochas, portanto, para áreas menos permeáveis, o escoamento superficial apresenta condições melhores, possibilitando assim a formação de canais e, consequentemente, aumentando a Dd, enquanto o oposto ocorre com rochas de granulometria mais espessa (ROCHA; KURTZ, 2001; SILVA et al., 2016).

O canal principal apresenta $42490 \mathrm{~m}$, sendo que a distância dos extremos do canal é de $25006 \mathrm{~m}$, resultando em um índice de sinuosidade (Is) de $1,7 \mathrm{Km} / \mathrm{Km}$, indicando que o canal tem formas transicionais, regulares e irregulares de acordo com a classificação proposta por Lana et al. (2001), ou seja, esse tipo de canal não favorece o transporte de sedimentos.

O gradiente de canais $(\mathrm{Gc})$ mede em porcentagem a declividade do curso d'água, tendo em vista que nessa bacia hidrográfica o valor encontrado foi de $0,51 \%$, é possível concluir que o relevo da área possui baixa declividade (HORTON, 1945), podendo ser considerado um relevo plano.

A extensão do percurso superficial da água de enxurrada (Eps) é a distância percorrida pela água até encontrar um canal permanente, sendo que esta bacia hidrográfica apresenta uma extensão $856 \mathrm{~m}$. O coeficiente de manutenção $(\mathrm{Cm})$ é um índice de grande importância no sistema de drenagem, ele representa a mínima área necessária que a bacia hidrográfica deve ter para manter perene cada metro de canal de drenagem que, neste caso é mediano, apresentando um $\mathrm{Cm}$ de $584 \mathrm{~m}^{2} / \mathrm{m}$.

A bacia hidrográfica em questão é de $6^{\underline{a}}$ ordem de ramificação, apresentando um total de 470 canais, dos quais $75,53 \%$ são de $1^{\text {a }}$ ordem que correspondem aos canais com presença de nascentes, onde o volume de água é baixo, $18,72 \%$ são de $2^{\underline{a}}$ ordem, os quais 
são formados por dois ou mais tributários de primeira ordem, 0,04\% são de 3aㅡ ordem, 0,01\% são de $4^{0}$ ordem, enquanto os de $5^{\underline{a}}$ e $6^{\underline{a}}$ ordem representam menos $0,01 \%$ dos canais.

A Tabela 2 apresenta os dados quantitativos dos canais em função da ordem do canal, enquanto a Figura 2 apresenta a distribuição espacial das ordens dos canais da bacia hidrográfica do rio Pariquera-Açu.

Tabela 2 - Classificação dos canais da bacia do rio Pariquera-Açu no baixo Ribeira de Iguape (SP)

\begin{tabular}{cccc}
\hline Ordem & $\begin{array}{c}\text { Número de } \\
\text { canais }\end{array}$ & Extensão $(\mathbf{k m})$ & \% de número de canais \\
\hline $1^{\underline{a}}$ & 355 & 333,24 & 50,71 \\
$2^{\underline{a}}$ & 88 & 114,86 & 26,42 \\
$3^{\text {a }}$ & 19 & 70,00 & 12,64 \\
$4^{\text {a }}$ & 5 & 37,40 & 4,69 \\
$5^{\underline{a}}$ & 2 & 36,38 & 5,4 \\
$6^{\underline{a}}$ & 1 & 0,17 & 0,14 \\
\hline
\end{tabular}

Fonte: Elaborado pelos autores.

Figura 2 - Ordem dos canais da bacia hidrográfica do rio Pariquera-Açu

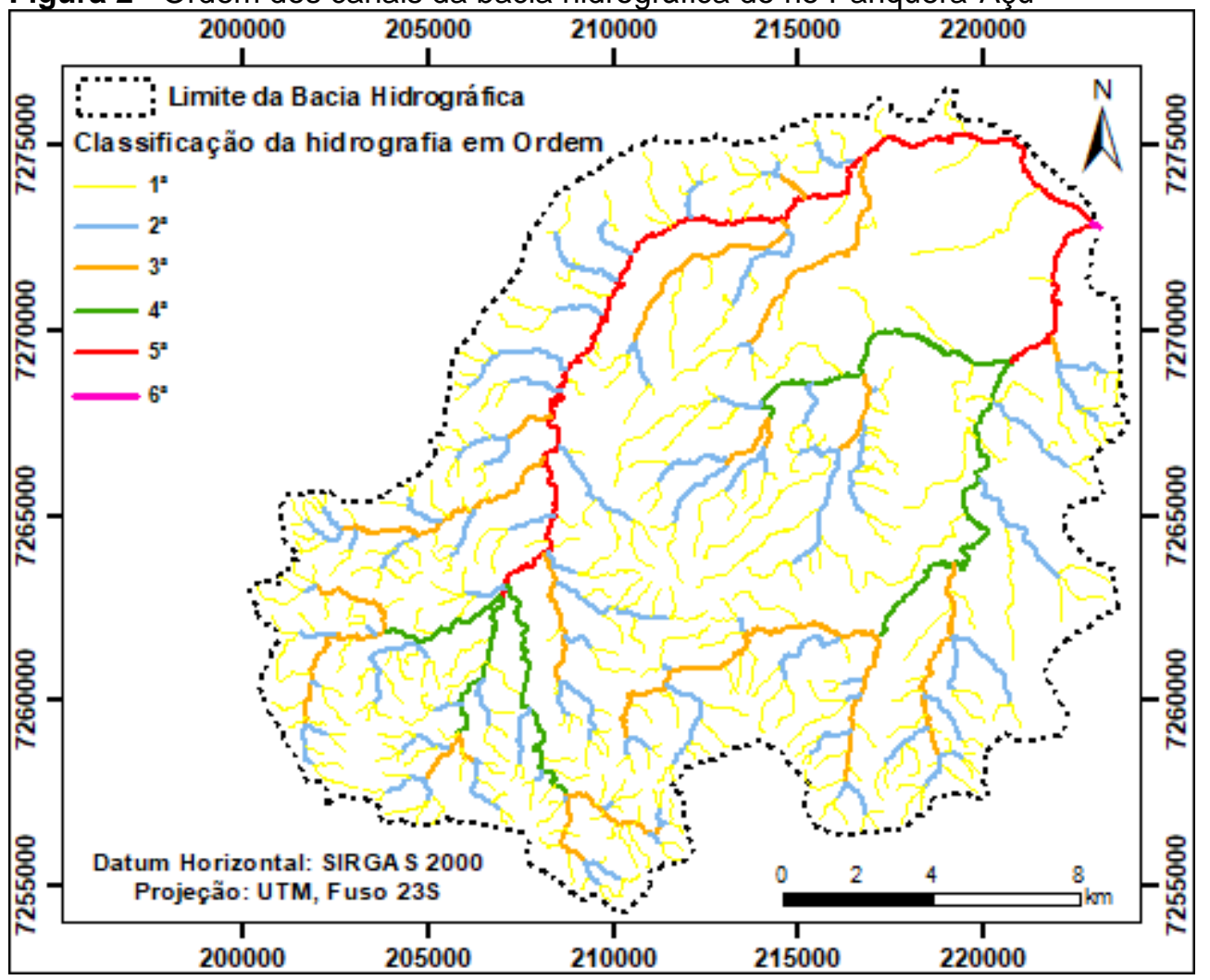

Fonte: Elaborado pelos autores.

A declividade média da bacia hidrográfica é de 12,3\%, permitindo classificar o relevo de acordo com o Sistema Brasileiro de Classificação de Solos da Embrapa (1999) como ondulado, com baixa declividade, isto é, apresenta menor velocidade de escoamento 
superficial das águas pluviais, diminuindo o lixiviamento do solo e riscos de erosão, sendo tal característica interessante para a agricultura.

A Figura 3 apresenta a distribuição espacial do coeficiente de rugosidade calculado para a bacia hidrográfica do rio Pariquera-Açu.

Figura 3 - Coeficiente de Rugosidade da bacia hidrográfica do rio Pariquera-Açu

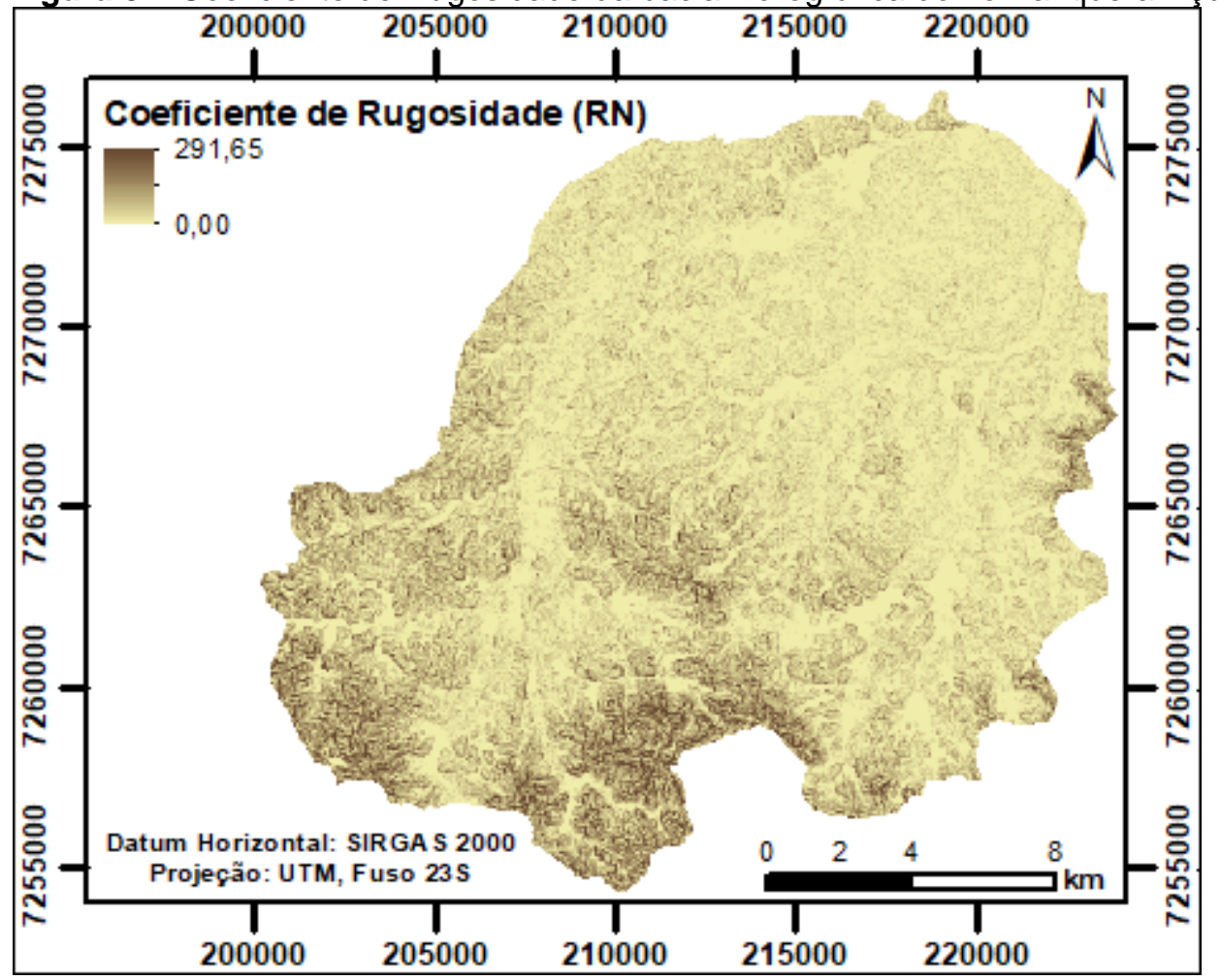

Fonte: Elaborado pelos autores.

O resultado do coeficiente de rugosidade médio da bacia hidrográfica do rio Pariquera-Açu é de 21,08. Na Figura 4 é ilustrado o histograma da distribuição do coeficiente de rugosidade em 4 classes, conforme metodologia proposta por Rocha e Kurtz (2001) para análise do potencial dos solos acerca do desenvolvimento de atividades antrópicas em função do relevo da bacia hidrográfica. 
Figura 4 - Histograma de distribuição do coeficiente de rugosidade (RN) em classes de aptidão

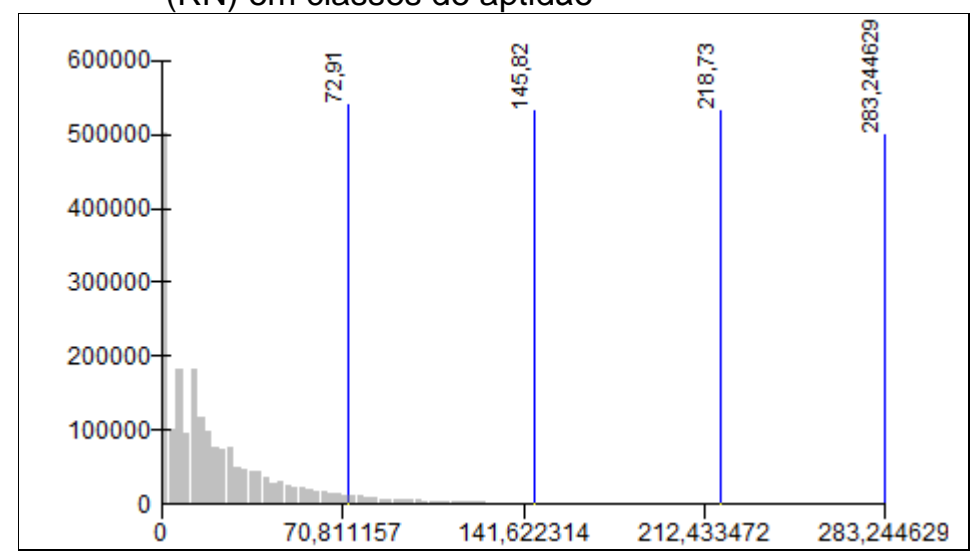

Fonte: Elaborado pelos autores.

De acordo com a Figura 4, é possível inferir que a bacia hidrográfica apresenta uso potencial para a agricultura, ou seja, terras adequadas para cultivos agrícolas e urbanização, como pode ser visto na Figura 5 (ROCHA; KURTZ, 2001; SILVA et al., 2016).

Figura 5 - Classes de aptidão para avaliar o uso potencial dos solos

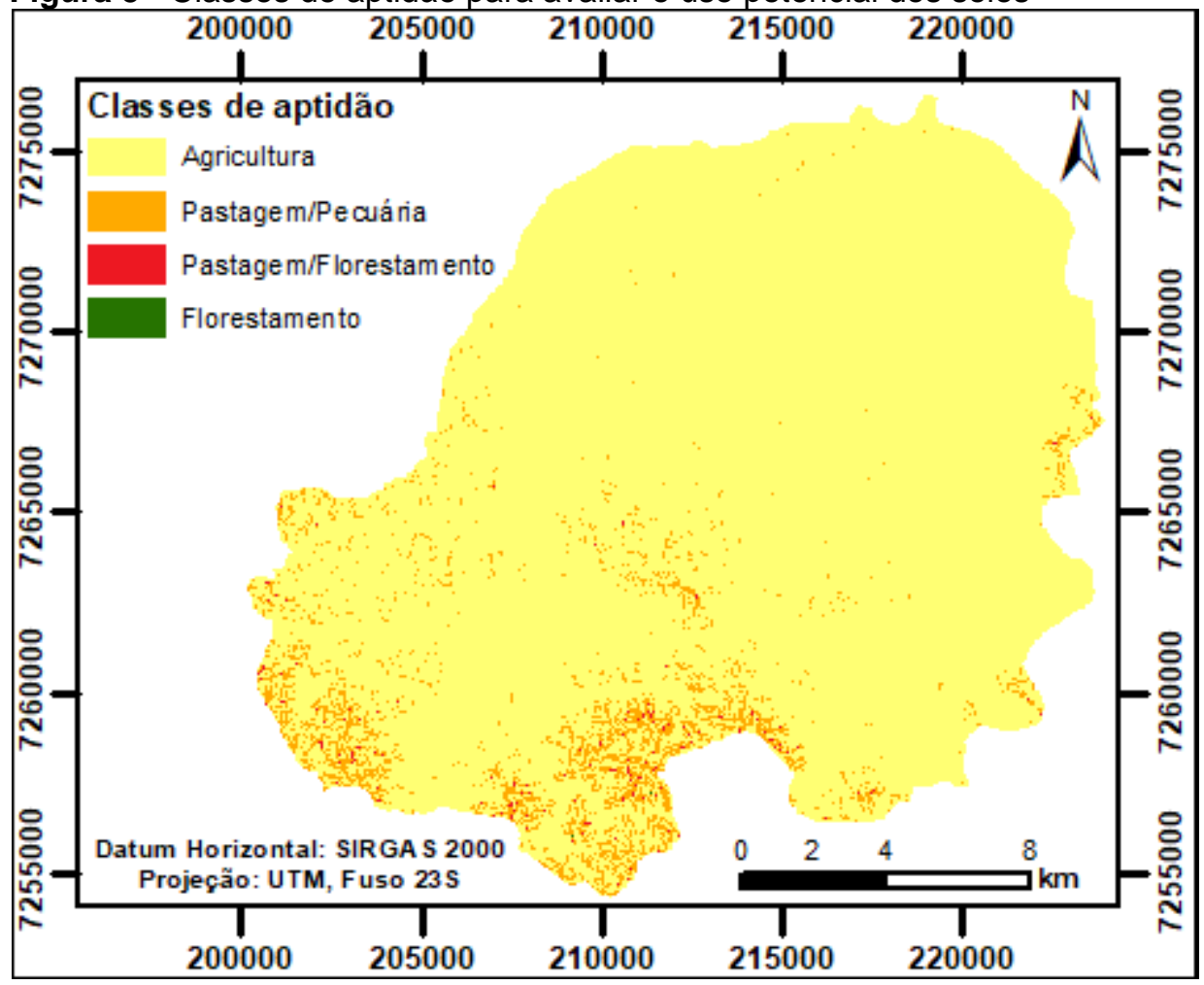

Fonte: Elaborado pelos autores.

De acordo com a Figura 5, verificou-se que $95,19 \%$ da área da bacia hidrográfica do rio Pariquera-Açu se classifica como apta para práticas agrícolas, enquanto $4,62 \%$ da área 
é adequada para pastagem e pecuária, sendo que apenas $0,19 \%$ é indicada para florestamento devido as características do relevo.

Independente da aptidão agrícola da bacia hidrográfica há necessidade de adoção de práticas agrícolas sustentáveis, visto que a jusante da bacia hidrográfica o relevo é plano e, segundo Silva et al. (2017), essa característica favorece possíveis carreamentos de sedimentos de forma contínua para o curso de água, podendo aumentar a probabilidade de ocorrência de enchentes e afetar as populações ribeirinhas que desenvolvem suas atividades as margens do rio Pariquera-Açu.

\section{CONCLUSÃO}

O índice de circularidade e compacidade indicam uma bacia hidrográfica alongada, com baixa tendência a ocorrência de enchentes que, em conjunto com a densidade de drenagem, classificada como mediana, permite inferir acerca da permeabilidade do substrato como média a alta com maior infiltração e menor escoamento da água.

O coeficiente de rugosidade (RN) permitiu classificar a bacia com aptidão para agricultura, visto que o relevo é suave e apresenta um RN com valores baixos indicando baixa probabilidade de sofrer os efeitos da erosão, entretanto, devido ao relevo suave, nas áreas próximas aos cursos de água podem ocorrer episódios de enchentes devendo estas áreas serem monitoradas pelos gestores públicos.

O estudo das características morfométricas de bacias hidrográficas com o auxílio de Sistema de Informações Geográficas é um importante instrumento de monitoramento e gestão dos recursos hídricos tanto para gestores públicos quanto para os demais interessados no uso e ocupação de bacias hidrográficas.

\section{REFERÊNCIAS}

ANTONELI, V; THOMAZ, E. L. Caracterização do meio físico da bacia do Arroio Boa Vista, Guamiranga-PR. Caminhos da Geografia, v. 8, n. 21, p. 46-58, 2007.

CAMPOS, S.; FELIPE, A. C.; CAMPOS, M.; RECHE, A. M. Geoprocessamento aplicado na caracterização morfométrica da microbacia do Ribeirão Descalvado-Botucatu, SP. IRRIGA, v. 1, n. 1, p. 52, 2015. https://doi.org/10.15809/irriga.2015v1n1p52

CHRISTOFOLETTI, A. Análise morfométrica de bacias hidrográficas. Notícia Geomorfologica, Campinas, v.18, n. 9, p. 35-64, 1969. 
CUNHA, D. G. F; CALIJURI, M. C. Análise probabilística de ocorrência de incompatibilidade da qualidade da água com o enquadramento legal de sistemas aquáticos - estudo de caso do rio Pariquera-Açu (SP). Engenharia Sanitária e Ambiental, v. 15, n. 4, p. 337-346, 2010. https://doi.org/10.1590/S1413-41522010000400006

DIAS, R. L.; OLIVEIRA, R. C. Caracterização socioeconômica e mapeamento do uso e ocupação da terra do litoral sul do estado de São Paulo. Sociedade \& Natureza, v. 27, n. 1, p. 111123, 2015. https://doi.org/10.1590/1982-451320150108

EMBRAPA, Empresa Brasileira de Pesquisa Agropecuária. Sistema brasileiro de classificação de solos. Brasília, DF, 1999. 412 p.

FAUSTINO, A. B.; RAMOS, F. F.; SILVA, S. M. P. Dinâmica temporal do uso e cobertura do solo na Bacia Hidrográfica do Rio Doce (RN) com base em sensoriamento remoto e SIG: uma contribuição aos estudos ambientais. Sociedade e Território, v. 26, n. 2, p. 18-30, 2014.

FERREIRA, R.; MOURA, M.; CASTRO, F. Uso de plataforma SIG na caracterização morfométrica da Bacia Hidrográfica do Rio Pancas-Brasil. Nativa, v. 3, n. 3, p. 210-216, 2015.

http://dx.doi.org/10.14583/2318-7670.v03n03a11

FRAGA, M. S.; FERREIRA, R. G.; SILVA, F. B.; VIEIRA, N. P. A.; SILVA, D. P.; BARROS, F. M.; MARTINS, I. S. B. Caracterização Morfométrica da Bacia Hidrográfica do Rio Catolé Grande, Bahia, Brasil. Nativa, v. 2, n. 4, p. 214-218, 2014. http://dx.doi.org/10.14583/2318$\underline{\text { 7670.v03n03a11 }}$

HORTON, R. Erosional development of streams and their drainage basins: hidrophysical approach to quatitative morphology. Geological Society of American Bulletin, v. 56. p. 807- 813, 1945.

IBGE, Instituto Brasileiro de Geografia e Estatística. Cidades. Disponível em: https://cidades.ibge.gov.br/. Acesso em: 03 abr. 2019.

LANA, C. L.; ALVES, J. M. P.; CASTRO, P. T. A. Análise morfométrica da bacia do rio Tanque, MG-Brasil. Revista Escola de Minas, v. 54, n. 2, 2001. https://doi.org/10.1590/S0370$\underline{44672001000200008}$

MACHADO, P. J. O.; TORRES, F. T. P. Introdução à hidrogeografia. São Paulo: Cengage Learning, 2012.

MELLO, C. R.; SILVA, A. M. Hidrologia: princípios e aplicações em sistemas agrícolas. 1.ed. Lavras: Editora UFLA, 2013. 455p.

MORELI, A. P.; PEREIRA, D. P.; SILVA, S. F. Caracterização morfométrica da sub-Bacia Hidrográfica do córrego Cancã, município de Venda Nova do Imigrante - ES, Brasil. Nucleus, v. 11, n. 2, p. 385-395, 2014. http://dx.doi.org/10.3738/1982.2278.945

MÜLLER, V. C. A quantitative geomorphology study of drainage basin characteristic in the Clinch Mountain Area. New York: Virginia and Tennesse. Dept. of Geology. n. 3, p. 30, 1953.

ROCHA, J. S. M.; KURTZ, S. M. J. M. Manual de manejo integrado de bacias hidrográficas. Santa Maria: Editora da UFSM, 2001. 282 p.

SANTOS, D. B.; VIDOTTO, M. L.; BERTINATTO, R.; SOUZA MARCON, G. R., FRIGO, E. P. Caracterização morfométrica da Bacia Hidrográfica do Rio São José, Cascavel, PR. Applied

Research \& Agrotechnology, v. 5, n. 2, p. 7-18, 2012. https://doi.org/10.5777/paet.v5i2.1659 
SCHUMM, S. A. Evolution of drainage systems and slopes in badlands at Perth Ambory, New Jersey. Bulletin of the Geological Society of America, Colorado, v. 67, p. 597-646, 1956.

SIGRH, Sistema Integrado de Gerenciamento dos Recursos Hídricos. Comitê da Bacia Hidrográfica do Ribeira de Iguape e Litoral Sul (CBH-RB). Disponível em:

http://www.sigrh.sp.gov.br/cbhrb/apresentacao. Acesso em: 03 abr. 2019.

SILVA, D. C. C.; ALBUQUERQUE FILHO, J. L.; SALES, J. C. A.; LOURENÇO, R. W. Use of morphometric indicators as tools for assessment watershed. Revista Brasileira de Geografia Física, v. 9, p. 627-642, 2016. https://doi.org/10.26848/rbgf.v9.2.p627-642

SILVA, D. C. C.; ALBUQUERQUE FILHO, J. L.; OLIVEIRA, R. A.; LOURENÇO, R. W. Methodology for potential degradation analysis of water resources in watershed. Caderno de Geografia, v. 27, p. 455-466, 2017. https://doi.org/10.5752/p.2318-2962.2017v27n50p455

STRAHLER, A. N. Hypsometric (area-altitude) analysis and erosional topography. Geological Society of America Bulletin. v. 63, n. 10, p. 1117-1142, 1952.

VILLELA, S. M.; MATTOS, A. Hidrologia aplicada. São Paulo: McGraw-Hill, 1975. 245p. 